\title{
40
}

\section{Toward an Integrated Account of Working Memory and Language}

\author{
Zhisheng (Edward) Wen and John W. Schwieter
}

\subsection{Introduction}

According to George Miller (1956), a pioneer of the "cognitive revolution"” and proponent of the buzzword concept of the "magical number seven," cognitive science in the modern sense had only started in the 1950s and gradually took shape in the mid-1970s. Based on Miller's (2003) historical account, cognitive science as a scientific field of study originally comprised six core disciplines, spanning psychology, linguistics, and neuroscience, as well as anthropology, artificial intelligence, and philosophy. Over the last half-century, cognitive scientists have probed into the underlying mechanisms and processes of human cognition, encompassing perception, attention, consciousness, reasoning, planning, learning, and memory, among many other topics. The six constituting disciplines have all flourished and complement each other, giving rise to a new set of interdisciplinary research agendas subsuming language acquisition and cognitive development, psycholinguistics and language processing, second language acquisition and bilingualism/multilingualism, and so forth.

Meanwhile, the concept of working memory had also made its debut appearance some 60 years ago (Miller et al., 1960, p. 65). But then, with the advent of the seminal model of working memory by the British cognitive psychologists Baddeley and Hitch (1974), ensuing research enthusiasm into its nature, structure, and implications for essential facets of human cognition has grown exponentially. Expanding waves of research endeavors from laboratories across the Atlantic (Andrade, 2001) have given rise to the propagation of a multitude of theoretical perspectives and models of working memory (Baddeley, 2012; Conway et al., 2007; Cowan, 2017; Logie et al.,, 2021; Miyake \& Shah, 1999). A majority of these influential 
working memory models are also featured in this current handbook, particularly in Part II, and they have been augmented with a particular focus on their unique ramifications for language acquisition and processing domains, as well as language impairments and intervention issues.

Building on these emerging patterns and insights gleaned from strands of previous research, we aim, in this concluding chapter, to briefly summarize the progress that has been made in both working memory and language sciences, with a view to further aligning putative working memory components and processes with nuanced language acquisition domains and processing activities. These reviews then culminate in an integrated account of working memory and an operational taxonomy for its implementations in future language and bilingualism research. It is hoped that through such an integrated account, we will not just reflect on the fruitful results of previous and current endeavors by key laboratories and scholars in the multiple fields of cognitive science, but also will prompt new and upcoming researchers from different disciplines to collaborate and contribute to the "working memory-language" enterprise (Wen, 2016).

\subsection{Unifying Theories of Working Memory}

In terms of theoretical conceptions of working memory, the pioneering multiple-component view by Baddeley and Hitch (1974) is arguably the most seminal model that has exerted extensive and far-reaching influence within psychology and beyond. Inspired by this standard model either directly or indirectly, at least a dozen other models have subsequently been proposed by working memory theorists and practitioners (Cowan, 2017; Logie et al., 2021; Miyake \& Shah 1999). Distinguished from Baddeley's classic model, for example, the "embedded-processes model" of working memory as proposed by Nelson Cowan (1999, 2019; see also Adams et al., this volume) has emphasized "focus of attention" as embedded in the activated part of the broader long-term memory system (aLTM). In a similar vein, the long-term working memory (LTWM) model focuses on the longterm knowledge structure and the efficient retrieval mechanisms that are essential for domain-specific expert performance (Adams \& Delany, this volume; Ericsson \& Delany, 1999; Ericsson, \& Kintsch, 1995).

Other cognitive psychologists such as Engle and Kane (2004) have underscored the executive control aspect of working memory in maintaining task-relevant information and inhibiting task-irrelevant distractors (see also Engle, 2002, 2018). In continental Europe, Barrouillet and Camos (2012, 2021, this volume) in their Time-Based Resource Sharing (TBRS) model have highlighted the temporal constraints and cognitive load of working memory tasks within the realm of human cognitive activities. Besides cognitive models, there are also other models that have been informed by distinctive perspectives including from neuroscience (see 
D’Esposito \& Postle, 2015; Eriksson, et al., 2015; Zahn et al., this volume; Purg et al., this volume) and computational modeling (see Burgess \& Hitch, 2005; Hitch et al., this volume), among many others that are not discussed here due to space limitations and scope.

Overall, the diverse approaches to working memory have, on the one hand, provided contrasting and complementary perspectives on the different facets of the construct. On the other hand, however, their seemingly disparate research paradigms and distinctive foci can sometimes lead to incompatible definitions of the very same construct from different laboratories, such as those held between the British versus the North American traditions (Andrade, 2001), not to mention the inconsistent research methodologies in variegated memory span tasks and assessment procedures (e.g., Burgoyne et al., this volume; Conway et al., 2005). Thus far, a generalizable model or theory of working memory that transcends multiple perspectives and models is still lacking (cf., Logie, 2019; Logie et al., 2021; Oberauer et al., 2018). Such a situation can sometimes cause confusion as countless other researchers from neighboring disciplines are looking for theoretical frameworks and measurement tools in cognitive science to investigate more practical issues of human cognition (such as academic learning or educational implications, cognitive training and interventions, etc.; Dehn, 2008; Fenesi et al., 2015; Forsberg et al., 2021; Novick et al., 2019).

With the goal of addressing these thorny issues and mitigating the confusion therein, scholars have recently attempted to mobilize concerted efforts to reconceptualize the working memory construct to be more applicable in practical-oriented domains such as academic learning or education (e.g., Dehn, 2008; Fenesi et al., 2015). For example, to reconcile the conflicting views of working memory across the different laboratories, recent years have witnessed the successful launch of the "adversarial collaboration" project initiated by Logie in Edinburgh and joined by three major working memory laboratories to investigate the same phenomenon and related issues (Cowan et al., 2020; Logie, et al., 2021). So far, encouraging progress has been achieved on several fronts toward building unifying theories of working memory, particularly in (1) extracting some unifying theories and characterizations of working memory from different research camps, contributing to a consensus understanding of the construct (Logie et al., 2021; Miyake \& Shah, 1999, 2021); and (2) identifying and compiling an extensive list of agreed-upon "benchmarks" for constructing working memory models (e.g., Oberauer et al., 2018).

Indeed, when multiple theories and models of working memory are thus systematically compared vis-à-vis each other, particularly when the proponents of different models are prompted to answer an edited set of common questions (e.g., Logie et al., 2021; Miyake \& Shah, 1999), it can be concluded that these distinctive perspectives and models are reflecting more of differences in research focus or emphasis, rather than fundamental disagreements (Forsberg et al., 2021). As suggested equivocally by Miyake and Shah 
Table 40.1 A unified understanding of working memory

\begin{tabular}{ll}
\hline \hline Nature of working memory & Structure of working memory \\
\hline $\begin{array}{l}\text { 1. Working memory is not a structurally } \\
\text { separate box or place in the mind or brain. }\end{array}$ & $\begin{array}{l}\text { 2. Working memory's maintenance } \\
\text { function is in the service of complex } \\
\text { cognition. }\end{array}$ \\
$\begin{array}{l}\text { 3. Capacity limits reflect multiple factors and } \\
\text { may even be an emergent property of the }\end{array}$ & $\begin{array}{l}\text { 4. Executive control is integral to working } \\
\text { memory functions. }\end{array}$ \\
$\begin{array}{l}\text { cognitive system. } \\
\begin{array}{l}\text { Neither a completely domain-general nor a } \\
\text { mempletely domain-specific view of working }\end{array}\end{array}$ & $\begin{array}{l}\text { 6. Long-term knowledge plays an integral } \\
\text { role in working memory performance. }\end{array}$ \\
\hline
\end{tabular}

(2021), the 6 themes derived from the 10 major theoretical models of working memory some 20 years ago (1999) are still valid and relevant today (see Table 40.1). These "consensus themes" thus constitute the common characterizations of working memory, which pave the ground for a unified account of the construct.

Among the "consensus themes," items 1, 3, and 5 offer more general and basic principles in understanding and conceptualizing working memory, while items 2, 4, and 6 spell out key putative components and processes of the construct. Together, they serve to provide essential criteria for arriving at a comprehensive and viable definition of working memory, which can now be stated as:

Working memory refers to the limited cognitive capacity that encompasses maintenance and executive control functions that are interacting with long-term knowledge.

It is evident from this definition that the capacity of working memory in simultaneous holding and processing of information is limited. This represents its signature feature (Carruthers, 2013; Klingberg, 2008), as opposed to the presumably "unlimited" long-term memory. Furthermore, working memory limitations are manifested in two ostensible ways (Baddeley, 1994). First, in terms of the memory span in our immediate consciousness, this capacity normally ranges between 7 unrelated units as originally conjectured by Miller (1956) and 4 chunks as later revised by Cowan (2001); also see Lu and Wen (this volume) for a distinction between the two in relation to language parsing. Then, information stored in our working memory is very short-lived, normally lasting for just around 5 to 20 seconds, unless rehearsed repeatedly (Waugh \& Norman, 1965). In their latest interpretation, these now-or-never bottleneck effects are constrained and shaped by the human brain and are pervasive and ubiquitous in human cognition (Christiansen \& Chater, 2008, 2016a).

Items 2, 4, and 6 in Table 40.1 further elaborate on the multidimensional or multifaceted nature of working memory, as opposed to being conceived as a unitary construct. Specifically, these three items represent the key 
components or the executive control functions subsumed by the working memory system. That is to say, working memory does not just serve to maintain information in immediate consciousness (item 2), but also encompasses such executive control or attentional functions (item 4; also see Engle, $2002 \& 2018)$ as articulatory rehearsal and memory retrieval, subsuming such executive processes as information updating, task-switching, and inhibitory control (Miyake \& Friedman, 2012; Miyake et al., 2000).

Furthermore, it needs to be pointed out that the contents stored and processed by the short-term storage buffers (the phonological loop and the visuospatial sketchpad, as perceived in Baddeley's original model) are normally domain-specific (such as auditory/sound and visuospatial materials), while the executive control functions operating on these materials are domain-general. In this sense, it may be best to conceive working memory as a multicomponent system that consists of both domain-specific storage buffers and domain-general executive control functions (Conway et al., 2005). Therefore, neither a completely domain-general nor a completely domainspecific view of working memory holds (item 4).

Finally, item 6 postulates that the contents of working memory storage and processing come from either external stimuli or input in the environment, or it can also be readily retrieved from the activated portion of long-term memory (aLTM). After processing, such information will then either get lost from working memory or be channeled back to the long-term memory knowledge base (Ellis, 1996). Conceived this way, working memory is rendered as a gateway that allows information to travel back and forth between itself and long-term memory, an idea that is embraced by most working memory theorists (Baddeley, 2012; Forsberg et al., 2021). Despite their elusive relationship, it is still necessary and beneficial to distinguish between short-term memory, working memory, and long-term memory in terms of their capacity, duration, and functions (e.g., Baddeley, 2012; Norris, 2017; cf. Cowan, 2008, 2019).

In short, these six consensus themes constitute the unifying characterizations of working memory that are fundamental to a comprehensive understanding of the construct gleaned from cognitive science. For this reason, they should be fully considered when the concept is to be defined, implemented, and/or incorporated into any conceptual framework or theoretical model of human cognition. As we will further argue next, these common characterizations of working memory have also lent great support to the integrated account that we are now elaborating as a viable framework to scrutinize its putative roles in more specific aspects of language acquisition, processing, impairments, and intervention.

\subsection{Integrating Science of Language}

At the other end of the "working memory-language nexus" (Wen, 2016, 2019), language sciences have also witnessed exponential developments 
and shifts of paradigms over the last 50 years parallel to working memory advances in cognitive science discussed above. In terms of theoretical paradigms, Chomsky's $(2005,2011)$ generative approach (e.g., the parameterprinciple and the merge paradigms; see also Hauser et al., (2002) maintains a central position within linguistics (Everaert et al., 2015) (cf., Christiansen \& Chater, 2017). Notwithstanding, its very core concept of a prewired language faculty (aka, Universal Grammar, UG) has been critically challenged by emerging alternative approaches (Dabrowska, 2015; Ellis, 2019) such as connectionist- (Joanisse \& McClelland, 2015), emergentist (MacWhinney, 1999; MacWhinney \& O'Grady, 2015; O’Grady, 2021), and usage-based (Tomasello, 2003), construction-oriented (Goldberg, 2003), functional approaches (Bybee, 2010; Trousdale \& Hoffman, 2013). In the fields of second language acquisition and bilingualism/multilingualism, similar trends are also taking shape, with more and more scholars subscribing to these alternative approaches (e.g., Atkinson, 2011; VanPatten et al., 2020).

Also similar to the working memory conundrum, diverse approaches to language and SLA/bilingualism are coexisting peacefully most of the time, with different schools of thought thriving prosperously with their own distinctive research paradigms and methodologies. Nonetheless, conversations between them are rare and they seldom endeavor in meaningful collaborations to explore similar issues. And at times, there are fierce, tense debates. For example, the recent "critique-reply-rejoinder" style exchanges (Kaneman, 2003) between the generative approaches (Rothman \& Slabakova, 2018; Slabakova et al., 2014, 2020) and the complex, dynamic, systems theory (CDST) approach (de Bot, 2015) to SLA demonstrate the stark divide between the conflicting epistemological stances regarding the three putative factors pertaining to language design and acquisition (Chomsky, 2005, 2011; Hauser et al., 2002; Yang et al., 2017):

1. Genetic endowment (Universal Grammar), which determines the general course of the development of the language faculty.

2. Experience (comprehensive input), which leads to (narrow) variations.

3. Principles of data analysis and computation efficiency.

In this respect, the generative camp tends to conceive Universal Grammar as the first and primary factor in language acquisition, thus relegating other factors such as input (experience) and computation efficiency to the periphery. On the contrary, the usage-based and functional accounts listed above (e.g., the CDST approach; Larsen-Freeman \& Cameron, 2008) are embracing the second factor, namely, experience or language exposure. Still, the emergentist account (MacWhinney \& O'Grady, 2015; O'Grady, 2012) and the processing accounts (Chafe, 1994; Hawkins, 2014, this volume; Jackendoff, 2007, 2011), have all emphasized the third factor, namely computation efficiency (disguised as working memory limitations; see Lu \& Wen, this volume) as the most critical factor that constrains and shapes language evolution, acquisition, and processing from phonology to 
grammatical structure (Christiansen \& Chater, 2016b, 2017; Gómez et al., submitted; O'Grady, 2017). In a similar vein, Liu and colleagues (2017; Xu \& Liu, this volume) and Gibson et al. (2019) have recently adopted the dependency grammar and linguistic typological perspectives in which they argue that computation efficiency constitutes the overarching principle of human language structure and linguistic complexity.

At the present, the jury is still out as to which school of thought may be most accurate ultimately. That said, it can be argued that, similar to the diverse approaches to working memory discussed in Section 40.3, these seemingly disparate approaches to language/linguistics/SLA also differ in their priorities or emphases in positioning the purported factors potentially explaining the process/route and final attainment of language acquisition, regardless of whether it is first language or second language acquisition.

Regarding these issues, it is our hope that multiple disciplines of linguistics, psychology, and neuroscience will join together in working toward constructing an "integrated science of language" that incorporates multidisciplinary perspectives, accounts for a range of methodologies, and illuminates and triangulates evidence (Christiansen \& Chater, 2016b, 2017; Walenski \& Ullman, 2005). It is also based on these integrated views of language sciences that we will now turn to discuss the operational taxonomy of working memory for language and bilingualism research.

\subsection{An Integrated Account of Working Memory, Language, and Bilingualism}

Though dominant research of working memory in cognitive science has mostly focused on its nature (capacity limitations) and structure (embedded components and subprocesses), studies exploring its relationship with and implications for language have created an important line of inquiry since the inception of the concept (e.g., Daneman \& Carpenter, 1980; Gathercole \& Baddeley, 1993). Over the years, strands of working memory-language research endeavors have gradually developed into fruitful lines of inquiry, such as those following Baddeley's multiple components view (Baddeley, 2003, this volume; Baddeley et al., 1998; Gathercole and Baddeley, 1993), and others that tap into the individual differences of working memory capacity (e.g., Caplan \& Waters, 1999; Daneman \& Carpenter, 1980; Just \& Carpenter, 1992). In recent years though, working memory-language models have emerged, flourished, and gained increasing prominence in laboratories based across the world (e.g., Contributors to this volume come from more than 20 countries/regions).

After some 50 years of empirical investigations and theoretical advances, we have now accumulated a growing body of both empirical and theoretical research probing the "working memory-language nexus" by researchers across the globe (also see Wen et al., forthcoming). The present handbook is 
a testament to these interdisciplinary endeavors. Building on emerging patterns, we believe that it is now time to comprehensively evaluate and scrutinize their research findings more closely and systematically, with a view to building an integrative account. Strides toward this integration are clearly demonstrated in the chapters of the current handbook. This integration is not only beneficial to the development of the two fields independently, but also illuminates issues related to other domains of cognitive science. In the following sections, we will focus on the two well-established strands of working memory-language explorations, namely, (1) a componentoriented approach that explores the relationship between phonological working memory and language acquisition as inspired by Baddeley's seminal multicomponent view; and (2) a process-oriented approach that examines the roles of finer-grained working memory executive functions in language processing. These reviews will then culminate in the integrative Phonological/Executive model as a viable taxonomy for implementing working memory in future language and bilingua research (Wen, 2016, 2019; Bunting \& Wen, forthcoming; Wen et al.,

\subsubsection{Phonological Working Memory and Language Acquisition}

Early experimental and developmental psycholinguistic research related to working memory has followed the multicomponent model of working memory by Baddeley and colleagues (Baddeley, 2003, 2017, this volume; Baddeley et al., 1998; Gathercole \& Baddeley, 1993). Their empirical explorations elaborated the key components of working memory as they each relate to native language acquisition domains as well as nonnative (i.e., second or third etc.) language learning (e.g., Atkins \& Baddeley, 1998; Baddeley, 2003, 2015, 2017). The majority of their early studies had targeted the relationship between the phonological loop (i.e., phonological working memory or phonological short-term memory) in language acquisition and development (Baddeley et al., 1998). Phonological working memory can be further demarcated into two main cognitive mechanisms: phonological (short-term) store and articulatory rehearsal. Simple versions of the storage-only memory span tasks such as the digit/letter span or the nonword repetition span have been demonstrated to provide a reliable approximation of phonological working memory (Gathercole 2006; Gathercole et al., 1994).

Since the cognitive mechanisms contained in phonological working memory play important roles in the subsequent consolidation and chunking of phonological forms (Ellis, 1996; Huang \& Awh, 2018), empirical studies have shown that phonological working memory is particularly related to the acquisition and development of lexical knowledge, grammatical knowledge, and collocational knowledge of the native language (see Llompart \& Dabrowska, 2020 for a recent review), and at early developmental stages of L2 oral skills (e.g., O'Brien et al., 2007; Granena \& Yilmaz, 
2019), L2 vocabulary knowledge (Service \& Simard, this volume), and L2 grammar development (French, 2006; Leseman \& Verhagen, this volume; McCormick \& Sanz, this volume). In view of its instrumental role in acquiring the novel phonological forms among monolingual and bilingual children and adults, phonological working memory, as characterized in this manner, is best positioned to be conceptualized as a "language learning device" (Baddeley et al., 1998; Papagno, this volume). On the reverse side, deficits in phonological working memory have been found to result in language learning delay among children (Gathercole \& Baddeley, 1990; Pierce et al., 2017), and adults' inability to acquire phonological forms of new words (Llompart \& Dabrowska, 2020).

\subsubsection{Executive Working Memory and Language Processing}

In contrast, cognitive psychologists probing the constraint effects of individual differences of working memory capacity have paid more attention to the relationship between the executive control functions subsumed by working memory (i.e., executive working memory, including its embedded cognitive mechanisms and processes; cf. Danemen \& Carpenter, 1980; Miyake \& Friedman, 2012) and their consequences for language processing activities. Particular focus has been given to sentence processing (Caplan \& Waters, 1999; Cunnings, this volume), and reading comprehension (Daneman \& Merikle, 1996; Peng et al., 2018). Researchers in these diverse paradigms generally opt to employ complex storage-plus-processing memory tasks in which participants are subject to dual tasks, either in the form of semantics/grammaticality judgments (i.e., the reading span task; Daneman \& Carpenter, 1980) or calculation judgments (the operation span task; Turner \& Engle, 1989), plus recalls of the final items in the ascending lists (also see Conway et al., 2005; Burgoyne et al., this volume). Both early and recent large-scale studies and meta-analyses have shown that individual differences in executive functions of working memory and the outcomes of reading comprehension are positively correlated (Daneman \& Merikle, 1996; Peng et al., 2018), and such a close relationship also exists between executive working memory and L2 comprehension and production (Linck et al., 2014; also see Wen \& Jackson, forthcoming).

\subsubsection{The Phonological/Executive Model}

From our discussion thus far, it can be seen that the main research camps of working memory have focused on either phonological or executive working memory, respectively, in specific domains and processing activities in language and bilingualism. Empirical explorations have tapped into their distinctive roles in various aspects of acquisition and processing, contributing finer-grain details to fulfilling the juxtapositioned alignments between these two key working memory components and processes with 
corresponding language domains and skills. These juxtapositions are then synthesized to culminate in the theoretical foundation of the integrated Phonological/Executive (P/E) Model (Wen, 2012, 2016, 2019; also see Wen \& Li, 2019; Wen \& Skehan, 2021). As such, the P/E model stipulates that phonological working memory underlies the acquisitional and developmental domains of language, such as the acquisition and development of lexical knowledge, grammatical and discourse knowledge, and collocational knowledge; while executive working memory modulates cognitively demanding language processes and subskills, such as language comprehension (Adams \& Delany, this volume), interaction (Li \& An, this volume), production/ performance (Skehan, this volume), and bilingual interpreting (Zheng \& Kuang, this volume).

\subsection{Conclusion and Future Directions}

Above, we have described the design features, structure, and functions of working memory as extracted from multidisciplinary perspectives of cognitive science, which are then further aligned with well-attested associations with specific domains and skills of first and second language acquisition and processing. Overall, although working memory and language sciences have both made substantial progress as separate and independent disciplines in both theory and methodology, the integration between them is still in its infancy (c.f., Wen, 2016; Williams, 2015). In view of the fact that both fields are core pillars of cognitive sciences (Miller, 2003), we have proposed an integrated account of working memory and language sciences couched within the P/E Model as a viable taxonomy framework to conceptualize and implement working memory in future language acquisition and bilingualism research. No doubt, interdisciplinary research efforts will be a driving force for future development in the further reintegration between the two disciplines. We thus end the chapter by proposing directions for future research.

For cognitive scientists and neuroscientists, as well as linguists and psycholinguists, future research can continue to use advanced and sophisticated scientific methods and technologies to unveil the distinctive roles of multiple working memory components and functions in specific language learning and processing activities, particularly finer-grained executive functions such as memory updating, task switching, and inhibition (Miyake \& Friedman, 2012), as well as the roles of the underexplored components of working memory such as the episodic buffer (Baddeley, 2015) and related or emerging functions such as binding and chunking (e.g., Baddeley, this volume; Baddeley et al., 2011; Huang \& Awh, 2018; Norris \& Kalm, 2021) and elaboration (Bartsch \& Oberauer, 2021). Such technologies as eye tracking, event-related potential technology (ERP), and functional magnetic resonance brain imaging technology (fMRI) can be applied to reveal the 
intricate relationship between working memory and language acquisition and processing (Bialystok, 2017; Purg et al., this volume; Zahn et al., this volume). That said, working memory-language researchers also need to conduct behavioral experimental design and research (through the use of correlational, experimental, and longitudinal research designs) to further explore their complex relationship (Wen, 2016).

Previous working memory and language research conducted in major working memory laboratories, in Britain, North America, Europe, and across the globe, has focused on the native language, that is, monolinguals for assessment purposes (Burgoyne et al., this volume). However, the majority of the world's population knows and speaks more than one language. To this end, we thus call on the linguistics and psycholinguistics community, as well as scholars of bilingualism/second language acquisition and specific language impairments to play a more proactive role in exploring second language-oriented working memory measures targeting bilingual/multilingual populations (e.g., Shin \& Hu, this volume; Wen et al., 2021), rather than passively relying on the existing research paradigms and measurement tools offered by cognitive psychology from a monolingual perspective (Juffs \& Harrington, 2011). It can be expected that perspectives based on bilingual advantage and cross-linguistic switching may provide innovative insights to illuminate the sophisticated working memory-language nexus that may not be available from monolingual-oriented studies alone. (Grundy \& Timmer, 2017)

Indeed, in the context of increasing globalization and cross-cultural communication, there are even more bilinguals or multilinguals than monolinguals (Grosjean \& Li, 2013). This means that studying bilingualism and cognition is becoming more and more important and critical (Altarriba \& Isurin, 2013; Schwieter, 2015, 2019), with some researchers calling for the bilingual/multilingual mind to be viewed as "the default" rather than the exception (Libben, 2017; Libben \& Schwieter, 2019). As suggested by Bialystok (2017), it may now be time to rethink the concept of working memory from this bilingual perspective. In this sense, we suggest that working memory-language research should begin to incorporate the "bilingual/multilingual turn"(cf. Ortega, 2013), and to further reveal the cognitive psychological processes of working memory in tandem with first and second or even third language acquisition and processing (Altarriba \& Isurin 2013; Wen et al., 2015).

Finally, given that both fields of working memory and language sciences have been embraced by diverse approaches, and that collaboration between theoretical and empirical adversaries is rare (cf. Kahneman, 2003; Ellemers, 2021), it is hoped that extended and programmatic collaborative efforts between multiple laboratories of working memory and language sciences can be further explored and mobilized to yield complementary and novel insights and contribute to theoretical integration and joint advancement (Cowan et al., 2020; see also Ellemers, 2021). Future endeavors can emulate 
the five guidelines listed in Ellemers et al. (2020) to integrate incompatible results from different groups into agreed-on new empirical research to test competing hypotheses by (1) leveling the playing field, (2) capitalizing on curiosity, (3) producing measurable progress, (4) working toward mutual gain, and (5) being aware of the downside alternative. For example, researchers can learn valuable lessons from the successful example of the "Working memory across the life span" collaborative project (Cowan et al., 2020; Doherty et al., 2019; Logie et al.,, 2021).

Of course, as both Kahneman (2003) and Ellemers (2021) cautioned, participating in collaborations in which opposing sides are brought together successfully requires "openness to new ideas rather than a focus on the achievement of specifically prescribed outcomes" (Ellemers, 2021, p. 17). Thus, to end on a positive note, it is our editors' sincere hope that the current handbook will achieve its dual goals in not only reporting the latest developments in working memory and language sciences research, but in leveling the field for more meaningful and seamless integration and collaboration from now on. These fruitful integrations would be the culmination of the ultimate joy and reward we shall embrace in putting together this enormous project despite all the adversities brought by the global pandemic.

\section{References}

Altarriba, J., \& Isurin, L. (Eds.), (2013). Memory, language, and bilingualism: Theoretical and applied approaches. Cambridge University Press.

Andrade, J. (2001). Working memory in perspective. Taylor \& Francis.

Atkins, P., \& Baddeley, A. (1998). Working memory and distributed vocabulary learning. Applied Psycholinguistics, 19, 537-552.

Atkinson, D. (2011). Alternative approaches to second language acquisition. Routledge.

Baddeley, A. (1994). The magical number seven: Still magic after all these years? Psychological Review, 101(2), 353-356.

Baddeley, A. (2003). Working memory and language: An overview. Journal of Communication Disorders, 36(3),189-208.

Baddeley, A. (2012). Working memory: Theories, models, and controversies. Annual Review of Psychology, 63, 1-30.

Baddeley, A. (2015). Working memory in second language learning. In Z. Wen, M. Mota, \& A. McNeill (Eds.), Working memory in second language acquisition and processing (pp. 17-28). Multilingual Matters.

Baddeley A. (2017). Modularity, working memory, and language acquisition. Second Language Research, 33(3), 299-311.

Baddeley, A., Allen, R., \& Hitch, G. (2011). Binding in visual working memory: The role of the episodic buffer. Neuropsychologia, 49(6), 1393-1400.

Baddeley, A., \& Hitch, G. (1974). Working memory. In G. Bower (Ed.), The psychology of learning and motivation (pp. 47-89). Academic Press. 
Baddeley, A., Gathercole, S., \& Papagno, C. (1998). The phonological loop as a language learning device. Psychological Review, 105, 158-173.

Barrouillet, P., \& Camos, V. (2012). As time goes by: Temporal constraints in working memory. Current Directions in Psychological Science, 21(6), 413-419.

Barrouillet, P., \& Camos, V. (2021). The time-based resource-sharing model of working memory. In R. Logie, V. Camos, \& N. Cowan (Eds.), Working memory: State of the science (pp. 85-115). Oxford University Press

Bartsch, L., \& Oberauer, K. (2021). The effects of elaboration on working memory and long-term memory across age. Journal of Memory $\&$ Language, $118,104215$.

Bialystok, E. (2017). The bilingual adaptation: How minds accommodate experience. Psychological Bulletin, 143, 233-262.

Bunting, M. F., \& Wen, Z. E. (forthcoming). Working memory in language and bilingual development. In R. Logie, Z. Wen, S, Gathercole, N. Cowan, \& R. Engle, (Eds.), Memory in science for society. Oxford University Press.

Burgess, N., \& Hitch, G. (2005). Computational models of working memory: Putting long term memory into context. Trends in Cognitive Sciences, 9, 535-541.

Bybee, J. (2010). Language, usage, and cognition. Cambridge University Press.

Caplan, D., \& Waters, G. (1999). Verbal working memory and sentence comprehension. Behavioral and Brain Sciences, 22(1), 77-126.

Carruthers, P. (2013). The evolution of working memory. Proceedings of National Academy of Sciences, 110(2), 10371-10378.

Chafe, W. (1994). Discourse, consciousness, and time. University of Chicago Press.

Chomsky, N. (2005). Three factors in language design. Linguistic Inquiry, 36(1), 1-22.

Chomsky, N. (2011). Language and other cognitive systems: What is special about language? Language Learning and Development, 7, 263-278.

Christiansen, M., \& Chater, N. (2008). Language as shaped by the brain. Behavioral and Brain Sciences, 31, 489-509.

Christiansen, M., \& Chater, N. (2016a). The now-or-never bottleneck: A fundamental constraint on language. Behavioral \& Brain Sciences, 39, e62.

Christiansen, M. \& Chater, N. (2016b). Creating language: Integrating evolution, acquisition, and processing. MIT Press.

Christiansen, M. \& Chater, N. (2017). Towards in integrated science of language. Nature Human Behaviour, 1, 163.

Conway, A., Jarrold, C., Kane, M., Miyake, A., \& Towse, J. (Eds.) (2007). Variation in working memory. Oxford University Press.

Conway, A., Kane, M., Bunting, M., Hambrick, D., Wilhelm, O., \& Engle, R. (2005). Working memory span tasks: A methodological review and user's guide. Psychonomic Bulletin \& Review, 12, 769-786.

Cowan, N. (1999). An embedded-processes model of working memory. In A. Miyake \& P. Shah (Eds.), Models of working memory: Mechanisms of active maintenance and executive control (pp. 62-101). Cambridge University Press. 
Cowan, N. (2001). The magical number 4 in short-term memory: A reconsideration of mental storage capacity. Behaviour and Brain Sciences, 24, 87-185.

Cowan N. (2008). What are the differences between long-term, short-term, and working memory? Progress in Brain Research, 169, 323-338.

Cowan, N. (2017). The many faces of working memory and short-term storage. Psychonomic Bulletin \& Review, 24(4), 1158-1170.

Cowan, N. (2019). Short-term memory based on activated long-term memory: A review in response to Norris (2017). Psychological Bulletin, 145 (8), 822-847.

Cowan, N., Belletier, C., Doherty, J., Jaroslawska, A., Rhodes, S., Forsberg, A., Naveh-Benjamin, M., Barrouillet, P., Camos, V., \& Logie, R. (2020). How do scientific views change? Notes from an extended adversarial collaboration. Perspectives on Psychological Science, 15, 1011-1025.

Dabrowska, E. (2015). What exactly is Universal Grammar, and has anyone seen it? Frontiers in Psychology, 6, 852.

Daneman, M., \& Carpenter, P. (1980). Individual differences in working memory and reading. Journal of Verbal Learning and Verbal Behaviour, 19, 450-466.

Daneman, M., \& Merikle, P. (1996). Working memory and language comprehension: A meta-analysis. Psychonomic Bulletin \& Review, 3, 422-433.

de Bot, K. (2015). Moving where? A reaction to Slabokov et al. (2014). Applied Linguistics, 36(2), 261-264.

D'Esposito M., \& Postle, B. (2015). The cognitive neuroscience of working memory. Annual Review of Psychology, 66, 115-142.

Dehn, M. (2008). Working memory and academic learning: assessment and intervention. Wiley.

Doherty, J., Belletier, C., Rhodes, S., Jaroslawska, A., Barrouillet, P., Camos, V., Cowan, N., Naveh-Benjamin, M., \& Logie, R. (2019). Dual-task costs in working memory: An adversarial collaboration. Journal of Experimental Psychology: Learning, Memory, and Cognition, 45, 1529-1551.

Ellemers, N. (2021). Science as collaborative knowledge generation. British Journal of Social Psychology, 60(1), 1-28.

Ellemers, N., Fiske, S., Abele, A., Koch, A., \& Yzerbyt, V. (2020). Adversarial alignment enables competing models to engage in cooperative theory building toward cumulative science. Proceedings of the National Academy of Sciences, 117, 7561-7567.

Ellis, N. (1996). Sequencing in SLA: Phonological memory, chunking, and points of order. Studies in Second Language Acquisition, 18, 91-126.

Ellis, N. (2019). Essentials of a theory of language cognition. Modern Language Journal, 103, 39-60.

Engle, R. (2002). Working memory capacity as executive attention. Current Directions in Psychological Science, 11, 19-23.

Engle, R. (2018). Working memory and executive attention: A revisit. Perspectives on Psychological Science, 13, 190-193. 
Engle, R., \& Kane, M. (2004). Executive attention, working memory capacity, and a two-factor theory of cognitive control. In B. Ross (Ed.), The psychology of learning and motivation (pp. 145-99). Elsevier.

Ericsson, K., \& Delaney, P. (1999). Long-term working memory as an alternative to capacity models of working memory in everyday skilled performance. In A. Miyake \& P. Shah (Eds.), Models of working memory: Mechanisms of active maintenance and executive control (pp. 257-297. Cambridge University Press

Ericsson, K., \& Kintsch, W. (1995). Long-term working memory. Psychological Review, 102, 211-245.

Eriksson, J., Vogel, E., Lansner, A., Bergström, F., \& Nyberg, L. (2015). Neurocognitive architecture of working memory. Neuron, 88(1), 33-46.

Everaert, M., Huybregts, M., Chomsky, N., Berwick, R., \& Bolhuis, J. (2015). Structures, not strings: Linguistics as part of the cognitive sciences. Trends in Cognitive Sciences 19, 729-743.

Fenesi, B., Sana, F., Kim, J. \& Shore, D. (2015). Reconceptualizing working memory in educational research. Educational Psychology Review, 27(2), 333-351.

Forsberg, A., Adams, E., \& Cowan, N. (2021). The role of working memory in long-term learning: Implications for childhood development. Psychology of Learning and Motivation, 74,1-45.

French, L. (2006). Phonological working memory and second language acquisition: A developmental study of francophone children learning English in Quebec. Edwin Mellen.

Gathercole, S. (2006). Nonword repetition and word learning: The nature of the relationship. Applied Psycholinguistics, 27(4), 513-543.

Gathercole, S., \& Baddeley, A. (1990). Phonological memory deficits in language disordered children: Is there a causal connection? Journal of Memory and Language, 29, 336-360.

Gathercole, S., \& Baddeley, A. (1993). Working memory and language. Erlbaum.

Gathercole, S., Willis C., Baddeley, A., \& Emslie, H., (1994). The children's test of nonword repetition: A test of phonological working memory. Memory, 2(2), 103-127.

Gibson, E., Futrell, R., Piantadosi, S., Dautriche, I., Mahowald, K., Bergen, L., \& Levy, R. P. (2019). How efficiency shapes human language. Trends in Cognitive Sciences, 23(5), 389-407.

Goldberg, A. (2003). Constructions: A new theoretical approach to language. Trends in Cognitive Sciences, 7(5), 219-224.

Gómez-Rodríguez, C., Christiansen, M., \& Ferrer-i-Cancho, R. (submitted). Memory limitations are hidden in grammar. https://arxiv.org/abs/1908 .06629 .

Granena, G., \& Yilmaz, Y. (2019). Phonological short-term memory capacity and L2 oral performance. Journal of Second Language Studies, 2, 317-335.

Grosjean, F., \& Li, P. (2013). The psycholinguistics of bilingualism. Wiley. 
Grundy, J., \& Timmer, K. (2017). Bilingualism and working memory capacity: A comprehensive meta-analysis. Second Language Research, 33, 325-340.

Hauser, M., Chomsky, N., \& Fitch, W. (2002). The faculty of language: What is it, who has it, and how did it evolve? Science, 298, 1569-1579.

Hawkins, J. (2014). Cross-linguistic variation and efficiency. Oxford University Press.

Huang, L., \& Awh, E. (2018). Chunking in working memory via content-free labels. Scientific Reports, $8(23)$.

Jackendoff, R. (2007). A parallel architecture perspective on language processing. Brain Research, 1146, 2-22.

Jackendoff, R. (2011). What is the human language faculty? Two views. Language, 87, 586-624.

Joanisse, M., \& McClelland, J. (2015). Connectionist perspectives on language learning, representation and processing. WIREs Cognitive Science, 6, 235-247.

Juffs, A., \& Harrington, M. (2011). Aspects of working memory in L2 learning. Language Teaching, 44, 137-166.

Just, M., \& Carpenter, P. (1992). A capacity theory of comprehension: Individual differences in working memory. Psychological Review, 99, 122-149.

Kahneman, D. (2003). Experiences of collaborative research. American Psychologist, 58, 723.

Klingberg, T. (2008). The overflowing brain: Information overload and the limits of working memory. Oxford University Press.

Larsen-Freeman, D., \& Cameron, L. (2008). Complex systems and applied linguistics. Oxford University Press.

Libben, G., \& Schwieter, J. W. (2019). Lexical organization and reorganization in the multilingual mind. In J. W. Schwieter (Ed.), The handbook of the neuroscience of multilingualism (pp. 297-312). Wiley-Blackwell.

Libben, M. (2017). Non-selective language activation and bilingualism as the default mental lexicon. In M. Libben, M. Goral, \& G. Libben (Eds.), Bilingualism: A framework for understanding the mental lexicon (pp. 103-122). Benjamins.

Linck, J., Osthus, P., Koeth, J., \& Bunting, M. (2014). Working memory and second language comprehension and production: A meta-analysis. Psychonomic Bulletin \& Review, 21(4), 861-883.

Liu, H., Xu, C., \& Liang, J. (2017). Dependency distance: A new perspective on syntactic patterns in natural languages. Physics of Life Reviews, 21, 171-193.

Llompart, M., \& Dabrowska, E. (2020). Explicit but not implicit memory predicts ultimate attainment in the native language. Frontiers in Psychology, 11, 569-586.

Logie, R. (2019). Converging sources of evidence and theory integration in working memory: A commentary on Morey, Rhodes, and Cowan (2019). Cortex, 112, 162-171. 
Logie, R., Belletier, C., \& Doherty, J. (2021). Integrating theories of working memory. In R. Logie, V. Camos, \& N. Cowan (Eds.), Working memory: State of the science (pp. 389-429). Oxford University Press.

Logie, R., Camos, V., \& Cowan, N. (2021), Working memory: State of the science. Oxford University Press.

MacWhinney, B. (1999). The emergence of language. Lawrence Erlbaum.

MacWhinney, B., \& O'Grady, W. (Eds.). (2015). The handbook of language emergence. Wiley-Blackwell.

Miller, G. (1956). The magical number of seven, plus or minus two: Some limits on our capacity for processing information. Psychological Review, 63, 81-97.

Miller, G. (2003). The cognitive revolution: A historical perspective. Trends in Cognitive Sciences, 7(3), 141-144.

Miller, G., Galanter, E., \& Pribram, K. (1960). Plans and the structure of behavior. Holt.

Miyake, A., Friedman, N., Emerson, M., Witzki, A., Howerter, A., \& Wager, T. (2000). The unity and diversity of executive functions and their contributions to complex "frontal lobe" tasks: A latent variable analysis. Cognitive Psychology, 41, 49-100.

Miyake, A., \& Friedman, N. (2012). The nature and organization of individual differences in executive functions: Four general conclusions. Current Directions in Psychological Science, 21(1), 8-14.

Miyake, A., \& Shah, P. (1999). Models of working memory: Mechanisms of active maintenance and executive control. Cambridge University Press.

Miyake, A., \& Shah, P. (2021). Foreword. In R. Logie, V. Camos, \& N. Cowan (Eds.), Working memory: State of the science (pp. vi-viii). Oxford University Press.

Norris, D. (2017). Short-term memory and long-term memory are still different. Psychological Bulletin, 143(9), 992-1009.

Norris, D., \& Kalm, K. (2021). Chunking and data compression in verbal short-term memory. Cognition, 208, 104534.

Novick, J., Bunting, M., Dougherty, M., \& Engle, R. (2019). Cognitive and working memory training: Perspectives from psychology, neuroscience, and human development. Oxford University Press.

Oberauer, K., Lewandowsky, S., Awh, E., Brown, G., Conway, A., Cowan, N., Donkin, C., Farrell, S., Hitch, G., Hurlstone, M., Ma, W., Morey, C., Nee, D., Schweppe, J., Vergauwe, E., \& Ward, G. (2018). Benchmarks for models of short-term and working memory. Psychological Bulletin, 144(9), 885-958.

O’Brien, I., Segalowitz, N., Freed, B., \& Collentine, J. (2007). Phonological memory predicts second language oral fluency gains in adults. Studies in Second Language Acquisition, 29, 557-581.

O'Grady, W. (2012). Three factors in the design and acquisition of language. Wiley Interdisciplinary Reviews: Cognitive Science, 3, 493-99.

O'Grady, W. (2017). Working memory and language: From phonology to grammar. Applied Psycholinguistics, 38(6), 1340-1343. 
O'Grady, W. (2021). Natural syntax: An emergentist primer. University of Hawaii at Manoa. http://ling.hawaii.edu/wp-content/uploads/OGradyNatural-Syntax-2021-1.pdf

Ortega, L. (2013). SLA for the 21st century: Disciplinary progress, transdisciplinary relevance, and the bi/multilingual turn. Language Learning, 63 (S1), 1-24.

Peng, P., Barnes, M., Wang, C., Wang, W., Li, S., Swanson, H., Dardick, W., $\&$ Tao, S. (2018). A meta-analysis on the relation between reading and working memory. Psychological Bulletin, 144, 48-76.

Pierce, L., Genesee, F., Delcenserie, A., \& Morgan, G. (2017). Variations in phonological working memory: Linking early language experiences and language learning outcomes. Applied Psycholinguistics, 38, 1265-1302.

Rothman, J., \& Slabakova, R. (2018). State of the scholarship: The generative approach to SLA and its place in modern second language studies. Studies in Second Language Acquisition, 40(2), 417-442.

Schwieter, J. W. (Ed.). (2015). The Cambridge handbook of bilingual processing. Cambridge University Press.

Schwieter, J. W. (Ed.). (2019). The handbook of the neuroscience of multilingualism. Wiley-Blackwell.

Slabakova, R., Leal, T., \& Liskin-Gasparro, J. (2014). We have moved on: Current concepts and positions in generative SLA. Applied Linguistics, 35, 601-606.

Slabakova, R., Leal, T., Dudley, A. \& Stack, M. (2020). Generative second language acquisition. Cambridge University Press.

Tomasello, M. (2003). Constructing a language: A usage-based theory of language acquisition. Harvard University Press.

Trousdale, G., \& Hoffmann, T. (Eds.). (2013). The Oxford handbook of construction grammar. Oxford University Press.

Turner, M., \& Engle, R. (1989). Is working memory task dependent? Journal of Memory and Language, 28, 127-154.

VanPatten, B., Keating, G., \& Wulff, S. (2020). Theories in second language acquisition: An introduction. Routledge.

Walenski, M., \& Ullman, M. (2005). The science of language. The Linguistic Review, 22, 327-346.

Waugh, N., \& Norman, D. (1965). Primary memory. Psychological Review, 72, 89-104.

Wen, Z. (2012). Working memory and second language learning. International Journal of Applied Linguistics, 22, 1-22.

Wen, Z. (2016). Working memory and second language learning: Towards an integrated approach. Multilingual Matters.

Wen, Z. (2019). Working memory as language aptitude: The Phonological/ Executive Model. In Z. Wen, P. Skehan, A. Biedron, S. Li, \& R. Sparks (Eds.), Language aptitude: Advancing theory, testing, research and practice (pp. 189-214). Routledge. 
Wen, Z., Baddeley, A., \& Cowan, N. (Forthcoming). Working memory in first and second language: A tale of two paradigms. Cambridge University Press.

Wen, Z., \& Jackson, D. (Forthcoming). Working memory capacity and functions. In L. Shaofeng, P. Hiver, \& M. Papi (Eds.), The Routledge handbook of second language acquisition and individual differences. Routledge.

Wen, Z., Juffs, A., \& Winke, P. (2021). Measuring working memory. In P. Winke \& T. Brunfaut (Eds.), The Routledge handbook of second language acquisition and testing (pp. 167-176). Routledge.

Wen, Z., \& Li, S. (2019). Working memory in L2 learning and processing. In J. W. Schwieter \& A. Benati (Eds.), The Cambridge handbook of language learning (pp. 365-389). Cambridge University Press.

Wen, Z., Mota, M., \& McNeill, M. (2015). Working memory in second language acquisition and processing. Multilingual Matters.

Wen, Z., \& Skehan, P. (2021). Stages of acquisition and the P/E Model of working memory: Complementary or contrasting approaches to foreign language aptitude? Annual Review of Applied Linguistics, 41, 6-24.

Williams, J. (2015). Working memory in SLA research: Challenges and prospects. In Z. Wen, M. Mota, \& A. McNeill (Eds.), Working memory in second language acquisition and processing (pp. 301-307). Multilingual Matters.

Yang, C., Crain, S., Berwick, R., Chomsky, N, \& Bolhuis, J. (2017). The growth of language: Universal Grammar, experience, and the principle of computation. Neuroscience and Biobehavioral Reviews, 81, 103-119.

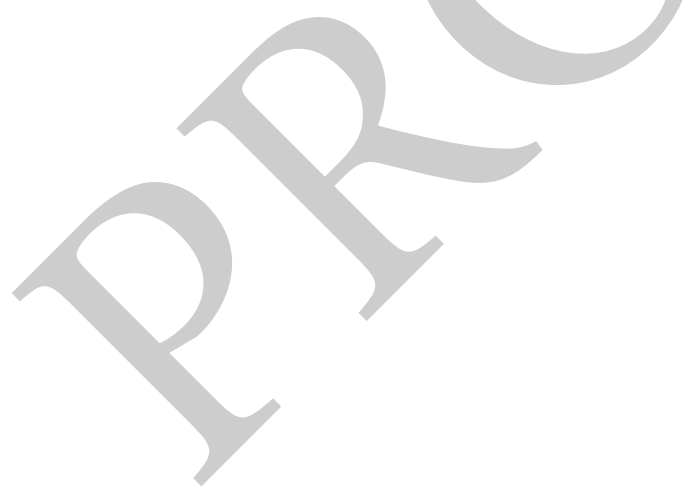

